\title{
The Effects of Respiratory-Muscle Training on Exercise in Older Women
}

\author{
Mark Watsford and Aron Murphy
}

\begin{abstract}
This research examined the effects of respiratory-muscle (RM) training on RM function and exercise performance in older women. Twenty-six women (60-69 yr of age) were assessed for spirometry, RM strength (maximal inspiratory and expiratory pressure), inspiratory-muscle endurance, and walking performance to a perceived exertion rating of "hard." They were randomly allocated to a threshold RM training group (RMT) or a nonexercising control group (CON) for 8 wk. After training, the 22\% (inspiratory) and 30\% (expiratory) improvements in RM strength in the RMT group were significantly higher than in the CON group $(p<.05)$. The RMT group also displayed several significant performance improvements, including improved within-group treadmill performance time (12\%) and reductions in submaximal heart rate $(5 \%)$, percentage of maximum voluntary ventilation $(16 \%)$, and perceived exertion for breathing (8\%). RM training appears to improve RM function in older women. Furthermore, these improvements appear to be related to improved submaximal exercise performance.
\end{abstract}

Keywords: aging, threshold loading, respiratory-muscle strength, walking

The age-related decline in skeletal-muscle integrity impairs physical performance, manifesting in decreased walking velocity and a potentially decreased capacity to perform activities of daily living. The reduced walking ability might also be related to a decrease in training capacity, causing further reductions in physical capacity. In comparison with men, women appear to be at greater risk of such decreases because of their lower initial strength and power levels (Janssen, Heymsfield, Wang, \& Ross, 2000). In an attempt to increase life satisfaction and quality of life, participation in strength training has been demonstrated as a valuable intervention to reduce the symptoms associated with sarcopenia (Newton et al., 2002).

In combination with the reductions in strength, older adults exhibit significantly reduced respiratory-muscle (RM) function, which is of similar magnitude to the younger, nonhealthy population with regard to pulmonary function and dyspnea (Janssens, Pache, \& Nicod, 1999). Several authors have presented prediction equations for RM strength in older adults, and although several predictive equations have included body mass and height (Black \& Hyatt, 1969; Enright, Kronmal, Manolio,

The authors are with the School of Leisure, Sport and Tourism, University of Technology, Sydney, Lindfield, New South Wales 2070 Australia. 
Schenker, \& Hyatt, 1994; McConnell \& Copestake, 1999), independently, these measures are not conclusive predictors of this variable. The mechanisms for a large portion of the interindividual variance in RM strength remain unclear; however, this variability might result from differences in technique, equipment, and population characteristics. Along with the evident relationships with body size, RM strength appears to be related to physical function in older adults (Watsford, Murphy, \& Pine, 2007). The stimulus of exercise appears to affect RM activity. Further to these issues, women have been reported to have a greater expiratory-flow limitation during exercise, along with greater encroachment on the ventilatory reserve, than men (McClaran, Harms, Pegelow, \& Dempsey, 1998). This might result in a marked difference in the ability to perform daily tasks, potentially affecting quality of life.

Clearly, traditional strength training has been demonstrated as a viable modality to promote gains in quality of life in the older population. It appears that specific strength training for the RM might also assist physical performance for older adults. RM training has been shown to improve RM strength and endurance in young, healthy humans (Romer, McConnell, \& Jones, 2002; Suzuki, Sato, \& Okubo, 1995; Volianitis et al., 2001), as well as individuals with respiratory, cardiac, and muscular deficiencies (Covey et al., 2001; Mancini, Henson, La Manca, Donchez, \& Levine, 1995; Weiner, Zeidan, et al., 1998). Furthermore, performance improvements in running, cycling, and repeated sprints have been reported by several researchers, indicating the potential athletic application of this relatively new training technique (Romer et al.; Volianitis et al., 2001). Mechanistically, RM training might reduce the competition for blood flow between the respiratory system and peripheral body segments, reduce the oxygen cost of respiration, and reduce the sensations of dyspnea (McConnell \& Romer, 2004; Sheel, 2002; Volianitis et al., 2000).

Several methods of RM training have been reported in the literature, but threshold loading has emerged as the most simple and efficient method of improving RM strength, with ensuing benefits for RM endurance performance (Sheel, 2002). Despite these reported performance enhancements, the evidence suggesting that RM training conclusively improves exercise performance remains controversial. Several authors have reported equivocal results after RM training. Regardless of improvements in RM strength, those authors reported no change in performance (Inbar, Weiner, Azgad, Rotstein, \& Weinstein, 2000; Sonetti, Wetter, Pegelow, \& Dempsey, 2001; Williams, Wongsathikun, Boon, \& Acevedo, 2002). Performance tasks that fail to elicit RM fatigue or have low levels of reproducibility have often been selected as the performance criteria, potentially contributing to the absence of augmentation.

One study examined the effects of RM training on RM function in a healthy older population (Belman \& Gaesser, 1988), but those researchers neglected to investigate the effects of this unique form of training on exercise performance. Therefore, because of the reported benefits of RM training, the similarities in adaptive properties between the muscles of young and older individuals, and a lack of available literature, investigation into the performance implications of threshold RM training is warranted in older adults. Because the respiratory system can contribute to fatigue during exercise, the aim of the current study was to examine the effects of RM training on respiratory-system characteristics and exercise performance in older adults. Older women were selected specifically because of their reportedly greater susceptibility to pulmonary limitations during exercise (Harms, 2006). The 
response to training was also examined to determine whether some individuals would benefit more from RM training. We hypothesized that RM training would improve RM strength and endurance in the older women, along with walking performance. Furthermore, we hypothesized that the improvements in walking performance would be specifically related to the changes in RM strength.

\section{Methods}

\section{Participants}

Twenty-six healthy, nonsmoking women age 60-69 years $(64.4 \pm 2.7$ years, 67.6 $\pm 10.1 \mathrm{~kg}, 161.7 \pm 4.8 \mathrm{~cm})$ gave their written informed consent to participate in the research. The participants completed a medical questionnaire (Healthscreen, Human Kinetics) to identify any medical conditions that excluded them from participating. They were excluded if they reported one or more uncontrolled health contraindications in Stage 1 of the questionnaire, such as severe osteoarthritis, osteoporosis, prior stroke, mental illness, or hypertension, or one or more uncontrolled exercise-induced signs of disease in Stage 2 of the questionnaire, such as angina, shortness of breath, or cramps. Throughout the participant-recruitment phase, 2 women were excluded from the study for medical reasons, and they were replaced with 2 healthy candidates.

\section{Procedures}

Testing consisted of spirometry, RM strength (maximal inspiratory and expiratory pressure), inspiratory-muscle endurance (IME), and an incremental treadmill test to a rating of perceived exertion (RPE; Borg, 1982) of "hard." This test included measures of heart rate (HR), oxygen consumption $\left(\mathrm{VO}_{2}\right)$, and RPE for breathing and peripheral effort. During this test, walking performance was assessed at a speed similar to that used during activities of daily living, $5.5 \mathrm{~km} / \mathrm{hr}$. All tests were implemented by the same trained technician, who offered standardized verbal encouragement throughout. After the baseline testing, the participants were randomly allocated into a RM training group (RMT) or a control group (CON) for an 8-week training program using a simple randomization method (Beller, Gebski, \& Keech, 2002). The research was approved by the human-research ethics committee at the University of Technology, Sydney. Based on previous research examining RM training, a large effect size $(0.7)$ was anticipated for the primary variable in the research (RM strength). Therefore, the minimum sample size per group was deemed to be 11 participants (Kraemer \& Thiemann, 1987).

\section{Spirometry}

All spirometry procedures were conducted using standards set by the Thoracic Society of Australia and New Zealand (Pierce \& Johns, 1995) with a turbine-flow spirometer (Bosch, Spiro 501). These procedures required the performance of at least three technically acceptable trials, with the largest score within $5 \%$ variation accepted for analysis, thus ensuring reliability of the results (Enright, Johnson, Connett, Voelker, \& Buist, 1991). Raw results were reported, and predicted values based on the findings of Gore et al. (1995) were examined for forced vital capacity 
(FVC) and forced expiratory volume in $1 \mathrm{~s}$ to ensure that no lung pathology was present. Lung pathology was suspected if the recorded score was $>20 \%$ lower than the predicted score. No participants presented with lung pathology. Peak expiratory flow and maximum voluntary ventilation (MVV) were measured to monitor any changes in flow rate and respiratory-volume dynamics after the training period.

\section{Respiratory-Muscle Strength}

Maximal inspiratory pressure $\left(\mathrm{P}_{I \max }\right)$ and maximal expiratory pressure $\left(\mathrm{P}_{\text {Emax }}\right)$ were measured using a portable mouth-pressure gauge (Spirovis, Cosmed, Italy). The Spirovis consists of an occluded airway that contains a 2-mm-diameter leak to prevent artificially elevated pressures from being developed by the mouth muscles while the glottis is closed. $\mathrm{P}_{\operatorname{Imax}}$ was measured from residual volume in negative units, and $\mathrm{P}_{\text {Emax }}$ was measured from total lung capacity in positive units. Participants remained in a seated position with a nose clip in place and were required to hold the sides of the mouth during $\mathrm{P}_{\mathrm{Emax}}$ assessment to prevent air from leaking out the side of the mouthpiece. They were required to breathe through the mouthpiece, attempting to "inhale/exhale the air as fast and hard as possible." The maximum pressure maintained for $1 \mathrm{~s}$ was recorded. Participants were familiarized with the procedures of this test and performed five trials followed by a 5-min rest period. All participants performed a minimum of three measured trials until several technically correct efforts were made. The highest value within 5\% variability was recorded, with the reliability of this procedure published previously with healthy participants (Larson \& Kim, 1987).

\section{Inspiratory-Muscle Endurance}

The endurance of the inspiratory muscles was assessed using a calibrated Powerlung RM-training device (Powerlung, USA). The Powerlung is a threshold-loading device consisting of a rigid plastic tube housing two rubber plungers, each held in place by a spring. To produce significant airflow the participant must generate respiratory pressures that overcome the threshold pressure $\left(\mathrm{P}_{\mathrm{TH}}\right)$, causing the spring to compress and the plunger to lift off its port. Although the Powerlung is able to place a resistance on both the inspiratory and expiratory muscles, the expiratory port was sealed to conduct a more specific examination of IME for this particular test. The calibration procedure involved using a digital manometer (Sper Scientific, USA) tapped into the body of the Powerlung device, with negative airflow passed through the inspiratory valve using a vacuum pump. The $\mathrm{P}_{\mathrm{TH}}$ of each arbitrary number of the inspiratory resistance was calculated in centimeters of water pressure $\left(\mathrm{cm} \mathrm{H}_{2} \mathrm{O}\right)$ and checked for linearity. A regression analysis performed on the relationship between these calibrated values and the arbitrary markings indicated that the levels on each device create a $\mathrm{P}_{\mathrm{TH}}$ that increases in a linear fashion for both the Powerlung Trainer $\left(r^{2}=.99\right)$ and Powerlung Sport $\left(r^{2}=.99\right)$.

IME was measured using a 2-min incremental threshold-loading test, following the procedures outlined by Fiz et al. (1998). The reliability and validity of this test has been documented, with strong test-retest reliability of .90 for maximal pressure maintained for a complete stage (Larson et al., 1999). A period of practice was provided for each participant, followed by $5 \mathrm{~min}$ of rest. In a seated position with 
a nose clip in place, each participant started the test at the same, low $\mathrm{P}_{\mathrm{TH}}(-13 \mathrm{~cm}$ $\mathrm{H}_{2} \mathrm{O}$ ). He or she was then instructed to correctly place the mouthpiece in the mouth before beginning inspiration and to make sure that this breath had completely finished before taking it out of the mouth for normal expiration. Breathing frequency was not constrained because it has been demonstrated to be unnecessary during incremental threshold loading (Martyn, Moreno, Pare, \& Pardy, 1987). After inspiring against this resistance for 2 min, participants underwent 2 min rest involving normal breathing. $\mathrm{P}_{\mathrm{TH}}$ was then increased by $8 \mathrm{~cm} \mathrm{H}_{2} \mathrm{O}$ for the next stage. Strong verbal encouragement was regularly given during the exercise periods. This process continued until a participant could no longer overcome the $\mathrm{P}_{\mathrm{TH}}$ and generate significant airflow. The maximum pressure sustained for a complete 2-min stage $\left(\mathrm{P}_{\mathrm{END}}\right)$ was recorded for analysis.

\section{Incremental Treadmill Walking Test}

To examine the physiological responses to increasing exercise intensity, a submaximal, incremental walking test on a motorized treadmill (Star Trac 4,500 series, USA) was undertaken. Before the test, the participants were required to perform a treadmill-walking warm-up consisting of 10 min of walking at various submaximal speeds. After the warm-up, participants received a detailed description of the treadmill-walking test, including the measurement variables, the criteria for termination of the test, and the rate of progression. The participants commenced walking at $4.5 \mathrm{~km} / \mathrm{hr}$. After $3 \mathrm{~min}$ at this speed, the treadmill speed was increased by $0.5 \mathrm{~km} / \mathrm{hr}$ for another $3 \mathrm{~min}$. During the final minute of each stage, $\mathrm{VO}_{2}, \mathrm{HR}$, RPE for walking (RPEW; Borg 6-20), and RPE for breathing (RPEB; Borg 6-20) were assessed. The test continued in this fashion until the participant recorded an RPEW or RPEB of 15 . This intensity of exercise related to a feeling of "hard" on the Borg 6-20 scale and corresponds to an approximate intensity of 70-80\% of maximal oxygen consumption (American College of Sports Medicine, 1990). This time was recorded as the time to RPE $15\left(\mathrm{~T}_{\mathrm{RPE} 15}\right)$.

Throughout the test, the participants were required to respire through a nonrebreathing valve (Hans-Rudolph, USA), which permitted the assessment of expired gases. Expired gases were sampled (Max-1, Physiodyne, USA) and averaged every $30 \mathrm{~s}$ during the final minute of each stage to permit the calculation of $\mathrm{VO}_{2}(\mathrm{ml}$. $\left.\mathrm{kg}^{-1} \cdot \mathrm{min}^{-1}\right)$. The gas-analysis equipment was calibrated immediately before each test, using gases of known composition.

Participants could volitionally terminate the test at any time. As an additional measure to ensure that the participants' exercise tolerance did not rapidly degrade without the opportunity to terminate the test, the RPE scale was displayed in front of each participant every 30 s once an RPEW or RPEB of 13 or higher was recorded. At the completion of the test, the participant performed a 5-min cool-down at a slow walking speed on the treadmill. HR was monitored throughout this period to ensure a decreasing pattern. A further 5-10 min of passive rest was undertaken by the participants after the walking.

Analysis of the treadmill-walking test was performed using a standard submaximal walking velocity for older women $(5.5 \mathrm{~km} / \mathrm{hr}$; Parise, Sternfeld, Samuels, \& Tager, 2004). Most of the participants continued beyond this velocity, but using this speed permitted comparison between groups, because all participants com- 
pleted this level of the test. Furthermore, data from the final completed stage for each participant were analyzed.

\section{Respiratory-Muscle Training}

RM training was performed with the Powerlung device, which permits inspiratory and expiratory threshold loading, with independent adjustment of the inspiratory and expiratory resistances. The RM training was performed at home for 8 weeks, with regular contact made with the participants to enhance adherence to the program. Before beginning the training, the participants were coached through one full training session under the supervision of the researcher, with corrections made to any problems in technique.

The participants in the RMT group were required to perform 12 training sessions per week that were spread over 6 days. Eight of the weekly sessions were focused toward a standard hypertrophy training response. Three sets of 10 repetitions were prescribed, with 1 min rest allocated between sets. A 10-repetition-maximum (10RM) load was used for these training sessions. Another two sessions during the week were endurance based, with the performance of 40 consecutive breaths at an intensity of 40RM. The remaining two sessions for the week were designed for strength development with five sets of five repetitions. An appropriately higher inspiratory and expiratory resistance was selected for these sessions (5RM). For each training load, participants were advised to take a 1-min rest between sets of breaths. Each training session was approximately 6 min in duration, with the endurance sessions lasting for approximately $10 \mathrm{~min}$.

The inspiratory training intensity for the standard sessions was initially set at $30 \%$ of $\mathrm{P}_{\operatorname{Imax}}$ with the expiratory intensity set to an arbitrary value on the Powerlung scale, which permitted the performance of 10RM for the standard training session. The progressive overload of training (participants were encouraged to increase inspiratory and expiratory resistance when the workload was tolerated) was documented in a logbook throughout the training period along with any other physical activity undertaken. The inspiratory resistance was increased by a quarter turn when the resistance failed to yield an RM response, whereas the expiratory resistance was increased at a slower rate, because of the disparities in the scaling systems on the device. Because of the relationship between expiratory resistance and the ensuing inspiration, it was not possible to control both variables during the training. Rather, the inspiratory resistance was designated as the focus for the training stimulus, with the expiratory resistance increased as the participants were able to tolerate the load. The residual volume after a resisted expiration is markedly compromised, resulting in a greater volume of air remaining in the lungs. This leads to a reduction in the force of the ensuing inspiration. This is because of the length-tension relationship of the inspiratory muscles (greater force output is permitted from smaller residual volumes; Clanton \& Diaz, 1995), which affects the force production. The method of increasing the resistance used in the current study was practical for the participants and reflects a training program that could be easily performed in the home environment. Because the primary focus for the study was inspiratory threshold training, the expiratory pressure was not calibrated, and the arbitrary numbers were merely used as a guide for expiratory resistance during the training period. 


\section{Control Group}

Participants in the CON group were not required to perform any form of physical training. The need for "sham" RM training for control-group members during clinical trials examining the efficacy of RM training has been mentioned previously (Romer et al., 2002; Volianitis et al., 2001), but some RM-training research has been done using a control group that did not participate in any form of sham training (Covey et al., 2001; Mancini et al., 1995). Furthermore, Wells, Plyley, Thomas, Goodman, and Duffin (2005) surmised that sham RM training might provide a small training stimulus, so inclusion of a control group that did not undertake any RM training was recommended. Therefore, it was concluded that $\mathrm{CON}$-group participants in the current study would not undertake any form of training at all.

\section{Statistical Analyses}

The data analysis was conducted using Statistical Package for the Social Sciences (SPSS) version 12. Descriptive statistics were calculated for all variables and are reported as $M \pm S D$. A one-way analysis of variance (ANOVA) was used to examine any differences between the groups at the pretest on the dependent measures. Repeated-measures ANOVA was calculated to compare main effects between the groups and interaction effects within each group. To analyze relationships between the change $(\Delta=$ posttest score - pretest score $)$ in RM function and other dependent variables after the training intervention, Pearson's product-moment correlation coefficients were calculated. Furthermore, to examine whether initial scores influenced the training effects, selected pretest scores were also included in the correlation analysis. An alpha level of $p<.05$ was selected to represent significance for all statistical procedures.

\section{Results}

\section{Physical Characteristics}

The physical data for the participants are presented in Table 1. There were no differences for any of the physical variables between any groups at the pretest. Furthermore, no differences or trends were evident in any group after the training period (Table 1).

Table 1 Physical Characteristics for All Participants, $M \pm S D$

\begin{tabular}{lcc}
\hline & Respiratory-muscle training, $\boldsymbol{n}=\mathbf{1 3}$ & Control, $\boldsymbol{n}=\mathbf{1 3}$ \\
\hline Age $($ years $)$ & $64.8 \pm 2.5$ & $64.0 \pm 2.9$ \\
Height $(\mathrm{cm})$ & $161.6 \pm 3.5$ & $161.9 \pm 6.0$ \\
Body mass $(\mathrm{kg})$ & & \\
$\quad$ pre & $67.5 \pm 11.1$ & $67.6 \pm 9.3$ \\
$\quad$ post & $66.9 \pm 10.9$ & $67.6 \pm 9.7$ \\
\hline
\end{tabular}




\section{Training Adherence}

The intensity of the training in the RMT group commenced at $30 \%$ of the pretest $\mathrm{P}_{\text {Imax }}$, and an arbitrary value was used for the expiratory loading. The progressive nature of the training ensured that the resistance was increased to $61 \% \pm 10 \%$ of pretest $\mathrm{P}_{\text {Imax }}$ in the final week of training. The loading placed on the expiratory valve was also increased progressively, but this value was based on the preset scale marked on the Powerlung device. This amount increased by $142 \% \pm 47 \%$ at the completion of the training. Adherence to the RM training was high, with $98 \% \pm$ $1 \%$ of sessions completed.

\section{Spirometry}

The raw data for the spirometry testing are presented in Table 2. There were no differences in spirometry scores between the groups at the pretest. Repeated-measures ANOVA revealed a significant between-groups effect for FVC in the RMT group ( $p$ $=.01$ ) along with a within-group interaction effect for peak expiratory flow in the RMT group $(p=.01)$. There were no changes in data for forced expiratory volume in $1 \mathrm{~s}$ for any group. Furthermore, MVV showed within-group improvements in the RMT group $(p=.05)$. There were no between-groups differences in any spirometry variables for the CON group.

\section{Respiratory-Muscle Strength and Endurance}

The results of the RM-strength tests are presented in Figure 1. The RM training completed by the RMT group was sufficient to produce between- and within-group

Table 2 Spirometry and Inspiratory-Muscle Endurance Results for All Participants, $M \pm S D$

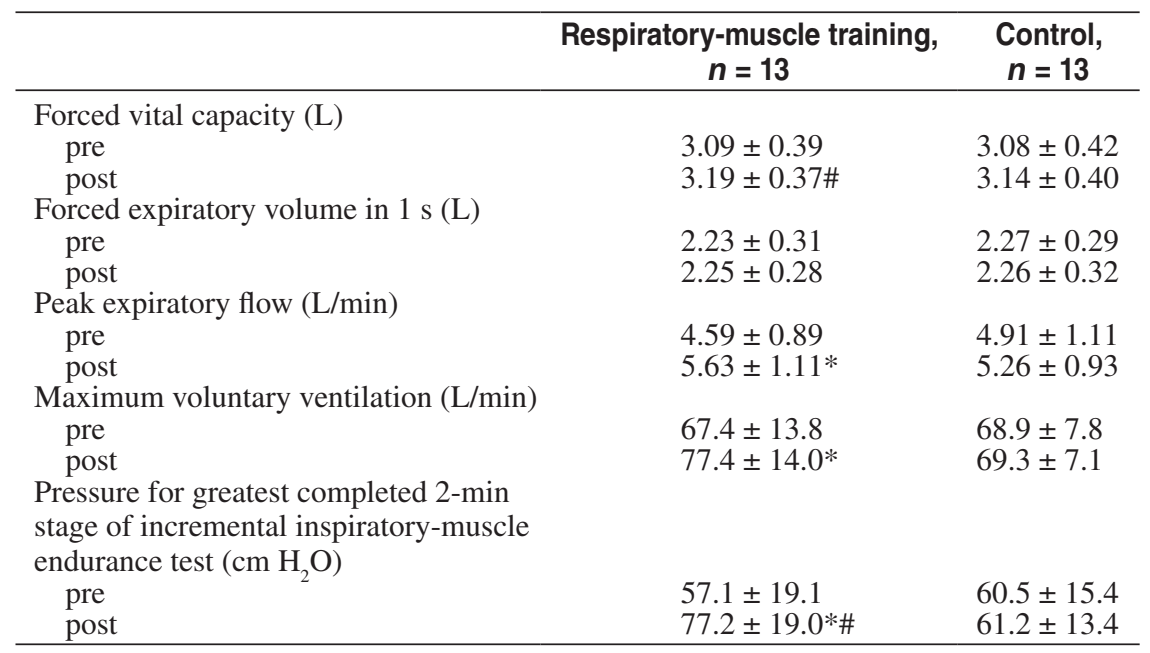

\#Significantly different than control group $(p<.05)$ * Significantly different than pretest $(p<.05)$. 

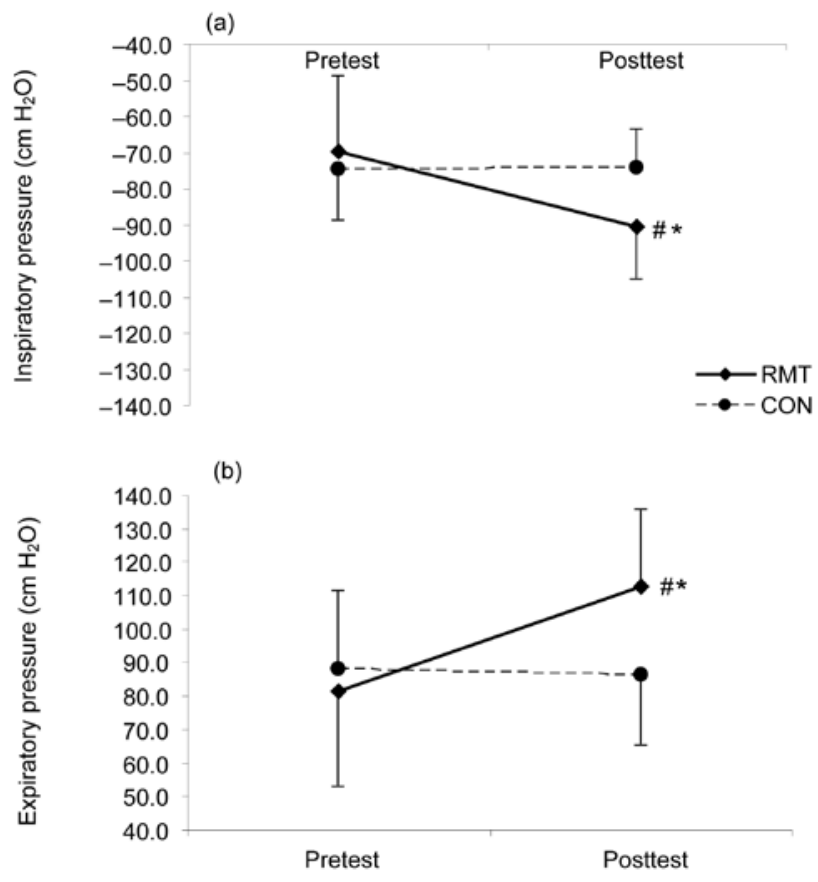

Figure 1 - Results for (a) inspiratory-muscle strength and (b) expiratory-muscle strength for all participants. Values are $M \pm S D$. RMT = group performing respiratory-muscle training; $\mathrm{CON}=$ control group. \#Significantly different than CON group, $p<.01$. *Significantly different than pretest, $p<.05$.

increases for $\mathrm{P}_{\operatorname{Imax}}$ and $\mathrm{P}_{\text {Emax }} . \mathrm{P}_{\text {Imax }}$ was $22 \%$ greater than in the CON group $(p=.01)$, and $\mathrm{P}_{\mathrm{Emax}}$ was $30 \%$ higher than in the CON group $(p=.01)$. When we examined the RM training response, a significant negative correlation was evident between pretest $\mathrm{P}_{\operatorname{Imax}}$ and $\Delta \mathrm{P}_{\text {Imax }}$ after the training $(r=-.60$; Table 3$)$. Furthermore, there was a similar relationship for expiratory-muscle strength, with pretest $P_{\text {Emax }}$ being significantly correlated with $\Delta \mathrm{P}_{\text {Emax }}$ after the training $(r=-.45)$. The correlation analysis also revealed that $\Delta \mathrm{P}_{\mathrm{Imax}}$ was related to $\Delta \mathrm{FVC}(r=-.41)$ and $\Delta \mathrm{MVV}(r=$ -.42 ; Table 3$)$, and $\Delta \mathrm{P}_{\text {Emax }}$ correlated with $\Delta \mathrm{MVV}(r=.42)$.

The results for the RM-endurance test are presented in Table 2. IME capacity did not display any between-groups differences at the pretest. $\mathrm{P}_{\mathrm{END}}$ was significantly greater in the RMT group than in the CON group after the training $(p=.02)$. There were no changes in IME in the CON group. The training response was examined with Pearson's correlation analysis, revealing that there was a significant negative interaction between pretest $\mathrm{P}_{\mathrm{END}}$ and $\Delta \mathrm{P}_{\mathrm{END}}$ after the training $(r=-.40)$. The relationship between $\Delta \mathrm{P}_{\text {Imax }}$ and $\Delta \mathrm{P}_{\mathrm{END}}$ was reinforced, with these variables exhibiting a strong correlation $(r=.75$; Table 3$)$. 


\section{Table 3 Pearson's Product-Moment Correlation Coefficients} for Respiratory-Muscle Function, Spirometry, and Performance

\begin{tabular}{lcccc}
\hline & $\begin{array}{c}\Delta \text { maximum } \\
\text { inspiratory } \\
\text { pressure }\end{array}$ & $\begin{array}{c}\Delta \text { maximum } \\
\text { expiratory } \\
\text { pressure }\end{array}$ & $\Delta \mathbf{P}_{\text {END }}$ & $\Delta \mathbf{T}_{\text {RPE15 }}$ \\
\hline Maximum inspiratory pressure pretest & $-.60^{*}$ & $.49^{*}$ & -.31 & .27 \\
Maximum expiratory pressure pretest & $.43^{*}$ & $-.45^{*}$ & .19 & -.28 \\
$\mathrm{P}_{\text {END }}$ pretest & $-.47^{*}$ & $.43^{*}$ & $-.40^{*}$ & .08 \\
$\Delta$ forced vital capacity & $-.41^{*}$ & .31 & -.38 & .20 \\
$\Delta$ forced expiratory volume in 1 s & .15 & -.25 & -.03 & -.08 \\
$\Delta$ peak expiratory flow & -.07 & .22 & -.14 & .38 \\
$\Delta$ maximum voluntary ventilation & $-.42^{*}$ & $.42^{*}$ & -.23 & .19 \\
$\Delta$ maximum inspiratory pressure & 1.00 & $-.87^{*}$ & $.75^{*}$ & $-.45^{*}$ \\
$\Delta$ maximum expiratory pressure & $-.87^{*}$ & 1.00 & $-.70^{*}$ & $.50^{*}$ \\
$\Delta \mathrm{P}_{\mathrm{END}}$ & $.75^{*}$ & $-.70^{*}$ & 1.00 & $-.39^{*}$ \\
$\Delta \mathrm{T}_{\mathrm{RPE} 15}$ & $-.45^{*}$ & $.50^{*}$ & $-.39^{*}$ & 1.00 \\
\hline
\end{tabular}

Note. $\mathrm{P}_{\mathrm{END}}=$ pressure for longest completed 2-min stage of incremental inspiratory-muscle endurance test; $\mathrm{T}_{\mathrm{RPE} 15}$ $=$ time to rating of perceived exertion of 15 during treadmill walking assessment.

*Significant correlation, $p<.05$.

\section{Incremental Walking Test}

The submaximal data for the walking test are presented in Table 4, with the results from the final stage of the incremental test presented in Table 5. There were no differences between groups before the training period for any of the variables. After repeated-measures ANOVA, $\mathrm{T}_{\mathrm{RPE} 15}$ showed a significant within-group increase in the RMT group $(p=.01)$, and in comparison with the control group, the data showed a strong tendency to improve but failed to reach significance $(p=.05)$. Furthermore, the RMT group recorded a significantly lower HR at $5.5 \mathrm{~km} / \mathrm{hr}(p=$ $.04)$ than the CON group, and \%MVV was significantly lower in the RMT than in the CON group at $5.5 \mathrm{~km} / \mathrm{hr}(p=.02)$. The amount of change in submaximal $\mathrm{VO}_{2}$ at $5.5 \mathrm{~km} / \mathrm{hr}$ after the training was significantly greater in the RMT group ( $p$ $=.03$ ), but the RMT group exhibited higher $\mathrm{VO}_{2}$ scores. RPEB during exercise was significantly lower in the RMT group at the submaximal assessment velocity ( $p=$ $.01)$. There were no within-group changes for RPEW. The relationships between RM strength, RM endurance, and exercise performance in the current study were confirmed with correlations, with $\Delta \mathrm{T}_{\mathrm{RPE} 15}$ being significantly correlated with $\Delta \mathrm{P}_{\text {Imax }}$ $(r=-.45), \Delta \mathrm{P}_{\text {Emax }}(r=.50)$, and $\Delta \mathrm{P}_{\mathrm{END}}(r=-.39)$.

\section{Discussion}

It is clear that specific RM training improves RM strength and endurance in community-dwelling older women. Furthermore, RM training appears to be beneficial during exercise, with several physiological adaptations evident. The findings of the current research are the first to report improved RM strength and 


\section{Table 4 Cardiovascular and Perceived-Exertion Results for} Treadmill Walking at $5.5 \mathrm{~km} / \mathrm{hr}, M \pm S D$

\begin{tabular}{lcc}
\hline & $\begin{array}{c}\text { Respiratory- } \\
\text { muscle training, } \\
\boldsymbol{n}=13\end{array}$ & $\begin{array}{c}\text { Control, } \\
\boldsymbol{n}=13\end{array}$ \\
\hline $\begin{array}{l}\text { Heart rate (beats/min) } \\
\text { pre }\end{array}$ & $116.8 \pm 13.3$ & $116.7 \pm 8.4$ \\
$\quad$ post & $111.5 \pm 13.6 \#$ & $116.9 \pm 8.0$ \\
$\begin{array}{l}\text { RPE for walking } \\
\text { pre }\end{array}$ & $12.7 \pm 1.8$ & $12.5 \pm 1.4$ \\
$\quad$ post & $12.2 \pm 2.4$ & $12.4 \pm 1.3$ \\
RPE for breathing & & \\
$\quad$ pre & $12.6 \pm 1.7$ & $12.6 \pm 1.4$ \\
post & $11.6 \pm 1.9 *$ & $12.2 \pm 1.2$ \\
Oxygen consumption $\left(\mathrm{ml} \cdot \mathrm{kg}^{-1} \cdot \mathrm{min}^{-1}\right)$ & $17.3 \pm 2.8$ & $15.5 \pm 1.8$ \\
$\quad$ pre & $16.4 \pm 1.8 \#$ & $15.7 \pm 1.8$ \\
post \\
$\begin{array}{l}\text { Maximum voluntary ventilation used }(\%) \\
\text { pre } \\
\text { post }\end{array}$ & $36.5 \pm 9.5$ & $35.5 \pm 10.3$ \\
\hline
\end{tabular}

Note. $\mathrm{RPE}=$ rating of perceived exertion (Borg units, 6-20 scale).

\#Significantly different than control group $(p<.05)$ * Significantly different than pretest $(p<.05)$.

\section{Table 5 Final-Stage Variables for Treadmill-Walking Performance} Test, $M \pm S D$

\begin{tabular}{lcc}
\hline & $\begin{array}{c}\text { Respiratory-muscle } \\
\text { training, } \boldsymbol{n}=\mathbf{1 3}\end{array}$ & Control, $\boldsymbol{n}=\mathbf{1 3}$ \\
\hline $\begin{array}{l}\text { Speed }(\mathrm{km} / \mathrm{hr}) \\
\text { pre }\end{array}$ & $6.23 \pm 0.78$ & $6.31 \pm 0.56$ \\
$\quad$ post & $6.50 \pm 0.74$ & $6.32 \pm 0.54$ \\
$\begin{array}{l}\text { Maximum voluntary ventilation used }(\%) \\
\quad \text { pre }\end{array}$ & $41.2 \pm 8.2$ & $42.4 \pm 10.3$ \\
$\quad$ post & $35.2 \pm 5.6$ & $42.0 \pm 10.5$ \\
$\begin{array}{l}\text { Time to rating of perceived exertion of } 15(\mathrm{~s}) \\
\text { pre }\end{array}$ & $772 \pm 295$ & $797 \pm 220$ \\
post & $865 \pm 292 *$ & $827 \pm 209$ \\
\hline
\end{tabular}

*Significantly different than pretest $(p<.05)$.

endurance in older adults after inspiratory and expiratory threshold loading. One previous article examined the role of isocapnic hyperpnea training, reporting that RM training might improve MVV in older adults (Belman \& Gaesser, 1988).

In accordance with previous research showing the plasticity of human muscle at all ages (Newton et al., 2002), specific threshold RM training resulted in significant strength development of the inspiratory and expiratory muscles (Figure 1). The RMT group demonstrated a significantly greater improvement than 
the CON group, indicating the effectiveness of the training for this population. Unfortunately, the global measures of $\mathrm{P}_{\operatorname{Imax}}$ and $\mathrm{P}_{\mathrm{Emax}}$ cannot differentiate between the relative contributions of the primary or accessory RM, but evidence suggests that the accessory RMs are responsible for a portion of the improvement in strength (Powers, Coombes, \& Demirel, 1997). The increases in $\mathrm{P}_{\mathrm{I} \max }$ observed in the current study for the RMT group (22\%) elevated the scores to levels observed in women as young as 30 years (Neder, Andreoni, Lerario, \& Nery, 1999). The threshold loading undertaken in the current study was also sufficient to significantly improve IME capacity in the RMT group in comparison with the CON group (Table 2). The improvements witnessed in the current study were in accordance with previous research, suggesting that threshold RM training improves endurance capacity of the inspiratory muscles (Covey et al., 2001; Volianitis et al., 2001). One of the mechanisms responsible for the improvement in endurance performance is the reliance on a lower proportion of maximum capacity at a given workload. This reduction in motor-unit recruitment might delay the onset of fatigue, thus enhancing endurance performance (McConnell \& Romer, 2004).

The improvements in RM strength affected spirometry performance. The amount of change in FVC and MVV was significantly correlated with the amount of change in $\mathrm{P}_{\text {Imax }}$, indicating the benefits of this mode of training for older adults (Table 4). The superior strength levels after the training resulted in an improved ability to inspire air forcefully, with benefits for the dynamic actions of spirometry. Typically, RM training does not elicit changes in pulmonary function (Suzuki et al., 1995; Weiner, Zeidan, et al., 1998); rather, respiratory volumes and flow rates are more affected by airway obstruction. Nonetheless, the current series of results suggests that because of the reduction in RM strength associated with age, RM training might result in improvements in spirometry in the older population. Despite the potential for concomitant improvements in performance, spirometry results were not related to the ability to perform exercise in the current study (Table 3).

The results from the correlation analysis suggest that individuals with lower initial strength levels recorded greater improvements after RM training (Table 3). Furthermore, the significant negative correlations between pretest score and amount of change in RM-strength measures indicated that $36 \%$ of the variance in the change in $\mathrm{P}_{\text {Imax }}$ was based on initial score, and this value was $20 \%$ for $\mathrm{P}_{\text {Emax }}$. Similarly, the amount of change in $\mathrm{P}_{\mathrm{END}}$ was related to the pretest score, with $16 \%$ of the variance accounted for. Such a result is yet to be reported in the literature examining RM training. These results highlight the need to identify RM weakness and the associated RM-strength benefits that individuals with poor RM strength and endurance might obtain. Furthermore, because RM strength and IME appear to be related to predicted aerobic capacity in older adults (Watsford, Murphy, Pine, \& Coutts, 2005) it is of paramount importance to identify such shortcomings. Therefore, it seems appropriate to include tests of RM strength in any physical examination for older women. Even though it is impossible to account for the large interindividual variance in RM-strength measures, many older individuals might benefit from the identification of this weakness and the prescription of an appropriate RM strengthtraining regimen. Naturally, results must be treated with caution because of the wide intersubject variability associated with these tests, but the potential benefits from within-subject longitudinal assessments provide a valid rationale for such testing. Previously, RM strength has been related to performance, with improved RM 
strength yielding increases in time to fatigue, time-trial performance, and dyspnea in healthy individuals (Romer et al., 2002; Suzuki et al., 1995; Volianitis et al., 2001) and individuals with respiratory, cardiac, or muscular deficiencies (Mancini et al., 1995; Sanchez Riera et al., 2001; Weiner, Gross, et al., 1998).

Further changes after the training period were evident during the treadmill test. There were several main-effect differences, along with several within-group changes occurring over time, suggesting that RMT affects performance in older women (Tables 4 and 5). The significant reduction in HR for the RMT group at 5.5 $\mathrm{km} / \mathrm{hr}$ indicates the potential impacts of RM training for the older population. In addition, the RMT group used a significantly reduced \%MVV at the submaximal walking-assessment speed after the training period $(-16 \%)$ in comparison with the CON group. Furthermore, the within-group $8 \%$ reduction in RPEB indicates the positive implications for dyspnea after RM training in older adults. Even though only $30-35 \%$ of MVV was used in the submaximal analysis, the results indicate that a reduction in relative respiratory work has associated benefits on submaximal performance. In combination with the reduction in submaximal $\mathrm{VO}_{2}$ in the RMT group, the reductions in \%MVV and RPEB suggest that RM training causes specific training adaptations in older adults. We propose that these posttraining alterations in breathing load would result in a reduction in the oxygen cost of breathing. Although it was not included in the assessment battery for this study, future research should include such a measure to gauge the effectiveness of RM training in this population.

Campbell's (1966) length-tension inappropriateness paradigm might partially explain the current results and the apparent reduction in respiratory demand. The enhanced posttraining RM strength results in a reduced motor-unit recruitment requirement for the RM, which might affect the intensity of dyspnea (McConnell \& Romer, 2004). More recently, Dempsey, Romer, Rodman, Miller, and Smith (2006) suggested that during high-intensity exercise in healthy participants, diaphragm fatigue can lead to reduced blood flow and $\mathrm{O}_{2}$ transport to the locomotor muscles, manifesting in peripheral fatigue. We postulate, however, that the altered respiratory dynamics associated with aging might reduce this critical intensity of exercise, resulting in RM fatigue at lower exercise intensities. The significant within-group improvement in $\mathrm{T}_{\mathrm{RPE} 15}$, along with the very strong between-groups trend $(p=.05)$ in the current research, suggests that RM training might help offset the reduction in limb blood flow during submaximal exercise for older women. The reduction in RPEB, along with the small changes in HR and \%MVV, has potential implications for the performance of low- to moderate-intensity activities. Based on the results of this study, after RM training older women might better tolerate the respiratory loads associated with these activities. Other researchers have indicated a link between the change in dyspnea and the change in performance (Romer et al., 2002; Weiner, Gross, et al., 1998), which further strengthens this speculation. Although the current results are promising, further research is required into the analysis of exercise of greater intensity than that measured in the current study, along with the specific examination of the mechanisms of such changes, including peripheral blood flow.

In addition to the physiological changes that occurred after the RM training period, there were many anecdotal reports from the participants in the RMT group regarding improved physical function. Specifically, individuals reported a greater 
capacity to walk up stairs without feeling breathless, improved concentration during recreational activities, a greater capacity to hold a note while singing, and the ability to walk briskly up hills without feeling tired. Such improvements might further affect quality of life and therefore improve life satisfaction in this age group.

The current results demonstrate the adaptive capacity of human muscle at any age and indicate that regular training for older adults can improve physiological results in functional performance. The apparent benefits resulting from RM training are achieved in a manner that appears to be ideal for older adults; that is, the training is performed in a seated position and requires only short periods of exertion. Naturally, RM training cannot replace the need for participation in whole-body exercise training, but it might be a useful supplement to other forms of training in older adults.

\section{Conclusion}

This article contributes to the growing body of research outlining the dynamic potential of the muscles of older adults. With improvements in maximal respiratory pressures of up to $30 \%$ in the RMT group, along with suggestions that individuals with lower initial RM strength yield a greater magnitude of improvement, this article highlights a training method that might greatly assist physical performance in older adults. This is the first time the results of a progressively overloading threshold RM-training program have been reported for older adults. The results suggest that the training program was well tolerated and that the intervention appeared to be safe and easily performed by the older adults. The improvements in RM strength and endurance appeared to affect various components of physical performance for the older women. Individuals with low initial RM strength appeared to benefit greatly from the training stimulus. Furthermore, because of the anecdotal reports of improved performance, RM training should be examined as a viable means of improving quality of life in older women. Furthermore, because of the lack of information about the physiological responses to RM training in older adults, further research is required to examine the effects of RM training on older men.

\section{Acknowledgments}

The authors would like to acknowledge the support of Powerlung. The company supplied the respiratory-muscle training devices. The results of the current study do not constitute endorsement of the product by the authors.

\section{References}

American College of Sports Medicine. (1990). American College of Sports Medicine position stand. The recommended quantity and quality of exercise for developing and maintaining cardiorespiratory and muscular fitness in healthy adults. Medicine and Science in Sports and Exercise, 22(2), 265-274.

Beller, E.M., Gebski, V., \& Keech, A.C. (2002). Randomisation in clinical trials. The Medical Journal of Australia, 177(10), 565-567.

Belman, M.J., \& Gaesser, G.A. (1988). Ventilatory muscle training in the elderly. Journal of Applied Physiology, 64(3), 899-905.

Black, L.F., \& Hyatt, R.E. (1969). Maximal respiratory pressures: Normal values and relationship to age and sex. The American Review of Respiratory Disease, 99, 696-702. 
Borg, G.A. (1982). Psychophysical bases of perceived exertion. Medicine and Science in Sports and Exercise, 14(5), 377-381.

Campbell, E.J. (1966). The relationship of the sensation of breathlessness to the act of breathing. In J.B.L. Howell (Ed.), Breathlessness (pp. 55-64). London: Blackwell Scientific.

Clanton, T.L., \& Diaz, P.T. (1995). Clinical assessment of the respiratory muscles. Physical Therapy, 75, 983-995.

Covey, M.K., Larson, J.L., Wirtz, S.E., Berry, J.K., Pogue, N.J., Alex, C.G., et al. (2001). High-intensity inspiratory muscle training in patients with chronic obstructive pulmonary disease and severely reduced function. Journal of Cardiopulmonary Rehabilitation, 21(4), 231-240.

Dempsey, J.A., Romer, L., Rodman, J., Miller, J., \& Smith, C. (2006). Consequences of exercise-induced respiratory muscle work. Respiratory Physiology \& Neurobiology, 151(2-3), 242-250.

Enright, P.L., Johnson, L.R., Connett, J.E., Voelker, H., \& Buist, A.S. (1991). Spirometry in the Lung Health Study. 1. Methods and quality control. The American Review of Respiratory Disease, 143(6), 1215-1223.

Enright, P.L., Kronmal, R.A., Manolio, T.A., Schenker, M.B., \& Hyatt, R.E. (1994). Respiratory muscle strength in the elderly. Correlates and reference values. Cardiovascular Health Study Research Group. American Journal of Respiratory and Critical Care Medicine, 149(2 Pt. 1), 430-438.

Fiz, J.A., Romero, P., Gomez, R., Hernandez, M.C., Ruiz, J., Izquierdo, J., et al. (1998). Indices of respiratory muscle endurance in healthy subjects. Respiration, 65, 21-27.

Gore, C.J., Crockett, A.J., Pederson, D.G., Booth, M.L., Bauman, A., \& Owen, N. (1995). Spirometric standards for healthy adult lifetime nonsmokers in Australia. The European Respiratory Journal, 8(5), 773-782.

Harms, C.A. (2006). Does gender affect pulmonary function and exercise capacity? Respiratory Physiology \& Neurobiology, 151(2-3), 124-131.

Inbar, O., Weiner, P., Azgad, Y., Rotstein, A., \& Weinstein, Y. (2000). Specific inspiratory muscle training in well-trained endurance athletes. Medicine and Science in Sports and Exercise, 32(7), 1233-1237.

Janssen, I., Heymsfield, S.B., Wang, Z.M., \& Ross, R. (2000). Skeletal muscle mass and distribution in 468 men and women aged 18-88 yr. Journal of Applied Physiology, 89(1), 81-88.

Janssens, J.P., Pache, J.C., \& Nicod, L.P. (1999). Physiological changes in respiratory function associated with ageing. The European Respiratory Journal, 13, 197-205.

Kraemer, H.C., \& Thiemann, S. (1987). How many subjects? Newbury Park, CA: Sage.

Larson, J.L., Covey, M.K., Berry, J., Wirtz, S., Alex, C.G., \& Matsuo, M. (1999). Discontinuous incremental threshold loading test: Measure of respiratory muscle endurance in patients with COPD. Chest, 115(1), 60-67.

Larson, J.L., \& Kim, M.J. (1987). Reliability of maximal inspiratory pressure. Nursing Research, 36(5), 317-319.

Mancini, D.M., Henson, D., La Manca, J., Donchez, L., \& Levine, S. (1995). Benefit of selective respiratory muscle training on exercise capacity in patients with chronic congestive heart failure. Circulation, 91, 320-329.

Martyn, J.B., Moreno, R.H., Pare, P.D., \& Pardy, R.L. (1987). Measurement of inspiratory muscle performance with incremental threshold loading. The American Review of Respiratory Disease, 135, 919-923.

McClaran, S.R., Harms, C.A., Pegelow, D.F., \& Dempsey, J.A. (1998). Smaller lungs in women affect exercise hyperpnea. Journal of Applied Physiology, 84(6), 1872-1881.

McConnell, A.K., \& Copestake, A.J. (1999). Maximum static respiratory pressures in healthy elderly men and women: Issues of reproducibility and interpretation. Respiration, 66(3), 251-258. 
McConnell, A.K., \& Romer, L.M. (2004). Dyspnoea in health and obstructive pulmonary disease: The role of respiratory muscle function and training. Sports Medicine (Auckland, N.Z.), 34(2), 117-132.

Neder, J.A., Andreoni, S., Lerario, M.C., \& Nery, L.E. (1999). Reference values for lung function tests. II. Maximal respiratory pressures and voluntary ventilation. Brazilian Journal of Medical and Biological Research, 32(6), 719-727.

Newton, R.U., Häkkinen, K., Häkkinen, A., McCormick, M., Volek, J., \& Kraemer, W.J. (2002). Mixed-methods resistance training increases power and strength of young and older men. Medicine and Science in Sports and Exercise, 34(8), 1367-1375.

Parise, C., Sternfeld, B., Samuels, S., \& Tager, I.B. (2004). Brisk walking speed in older adults who walk for exercise. Journal of the American Geriatrics Society, 52(3), 411-416.

Pierce, R., \& Johns, D.P. (1995). Spirometry: The measurement and interpretation of ventilatory function in clinical practice. Melbourne, Australia: National Asthma Campaign Ltd.

Powers, S.K., Coombes, J., \& Demirel, H. (1997). Exercise training-induced changes in respiratory muscles. Sports Medicine (Auckland, N.Z.), 24(2), 120-131.

Romer, L.M., McConnell, A.K., \& Jones, D.A. (2002). Effects of inspiratory muscle training upon recovery time during high intensity, repetitive sprint activity. International Journal of Sports Medicine, 23(5), 353-360.

Sanchez Riera, H.S., Rubio, T.M., Ruiz, F.O., Ramos, P.C., Otero, D.D.C., Hernandez, T.E., et al. (2001). Inspiratory muscle training in patients with COPD: Effect on dyspnea, exercise performance and quality of life. Chest, 120(3), 748-756.

Sheel, A.W. (2002). Respiratory muscle training in healthy individuals. Sports Medicine (Auckland, N.Z.), 32(9), 567-581.

Sonetti, D.A., Wetter, T.J., Pegelow, D.F., \& Dempsey, J.A. (2001). Effects of respiratory muscle training versus placebo on endurance exercise performance. Respiration Physiology, 127(2-3), 185-199.

Suzuki, S., Sato, M., \& Okubo, T. (1995). Expiratory muscle training and sensation of respiratory effort during exercise in normal subjects. Thorax, 50(4), 366-370.

Volianitis, S., McConnell, A.K., Koutedakis, Y., McNaughton, L., Backx, K., \& Jones, D.A. (2000). Effects of inspiratory muscle training on dyspnoea during rowing [abstract]. The Journal of Physiology, 523(Suppl.), 220P-221P.

Volianitis, S., McConnell, A.K., Koutedakis, Y., McNaughton, L., Backx, K., \& Jones, D.A. (2001). Inspiratory muscle training improves rowing performance. Medicine and Science in Sports and Exercise, 33(5), 803-809.

Watsford, M.L., Murphy, A.J., \& Pine, M.J. (2007). The effects of ageing on respiratory muscle function and performance in older adults. Journal of Science and Medicine in Sport, 10(1), 36-44.

Watsford, M.L., Murphy, A.J., Pine, M.J., \& Coutts, A.J. (2005). The effect of habitual exercise on respiratory-muscle function in older adults. Journal of Aging and Physical Activity, 13(1), 34-44.

Weiner, P., Gross, D., Meiner, Z., Ganem, R., Weiner, M., Zamir, D., et al. (1998). Respiratory muscle training in patients with moderate to severe myasynthenia gravis. The Canadian Journal of Neurological Sciences, 25, 236-241.

Weiner, P., Zeidan, F., Zamir, D., Pelled, B., Waizman, J., Beckerman, M., et al. (1998). Prophylactic inspiratory muscle training in patients undergoing coronary artery bypass graft. World Journal of Surgery, 22, 427-431.

Wells, G.D., Plyley, M., Thomas, S., Goodman, L., \& Duffin, J. (2005). Effects of concurrent inspiratory and expiratory muscle training on respiratory and exercise performance in competitive swimmers. European Journal of Applied Physiology, 94(5-6), 527-540.

Williams, J.S., Wongsathikun, J., Boon, S.M., \& Acevedo, E.O. (2002). Inspiratory muscle training fails to improve endurance capacity in athletes. Medicine and Science in Sports and Exercise, 34(7), 1194-1198. 